\title{
INFLUENZA VACCINATION COVERAGE IN ENGLAND, 2000-2008
}

\author{
R G Pebody (richard.pebody@hpa.org.uk)1, F Begum¹,2, P Gates², K Noakes², D Salisbury² \\ 1. Health Protection Agency, Centre for Infections, London, United Kingdom \\ 2. Immunisation Branch, Department of Health, London, United Kingdom
}

Dear Editor,

We read with interest the article by $P$ Blank and colleagues on "Trends in influenza vaccination coverage rates in the United Kingdom over six seasons" published on 23 October 2008 [1].

The authors' study sets out to measure vaccine uptake over six seasons, with a secondary objective to ascertain motivations to be vaccinated. Between 2001 and 2007, they undertook annual household surveys by telephone interview in the UK. In their results, the authors describe a significant decline in vaccine uptake in those 65 years and more in age from $78.1 \%$ to $65.3 \%$ with evidence of year to year variation.

For several years, the Health Protection Agency on behalf of Department of Health has undertaken routine annual uptake monitoring of the seasonal influenza vaccination programme in England in order to provide an annual estimate of uptake in targeted groups. Data are now collected on registered patients in all general practices in England using a web-based reporting system. Many practices use automated extraction procedures based on standard queries. A detailed description of the methods used to collect the data is available [2].

In 2007-8, 95\% of 8,375 GP practices in England took part in data collection. The sample size (registered patients, aged 65 and over) was $8,071,671$ ). The national mean uptake in those 65 years and above in England was 74\%, approaching the WHO target of $75 \%$. Uptake levels have reached a plateau after the steady increase from $65 \%$ when the over-65-year-old programme was introduced in 2000 (Table 1). Data are published [3]
What might be the explanation for the discordance in the trend findings? As Blank et al discuss, their telephone study did have a large number of non-respondents (6\% response rate), with the consequent potential for selection bias. In addition, the approach of self-reporting vaccination status can result in misclassification bias. Finally, the relatively small annual sample for the 65+ subgroup ( $<400$ persons) will result in power limitations.

Telephone survey data can be a useful study tool. Our direct data allows the authors to validate the accuracy of their findings. There are discrepancies, indicating care needs to be taken when interpreting these results.

\section{References}

1. Blank PR, Freiburghaus AU, Schwenkglenks M, Szucs TD. Trends in influenza vaccination coverage rates in the United Kingdom over six seasons from 2001-2 to 2006-7. Euro Surveill. 2008;13(43):pii=19014. Available from: http:// www.eurosurveillance.org/ViewArticle.aspx?ArticleId=19014

2. Begum F, Pebody R. Influenza vaccination uptake in the 65 years and above and under 65 year olds at risk in England, 2007-8. Influenza Immunisation Uptake Monitoring Programme. Report commissioned by the Department of Health. Available from: http://www.hpa.org.uk/web/HPAwebFile/ HPAweb C/1213083216553

3. NHS Immunisation Statistics. England 2007-8. Available from: http://www. ic.nhs.uk/statistics-and-data-collections/health-and-lifestyles/immunisation/ nhs-immunisation-statistics-england-2007-08-\%5Bns\%5D

This article was published on 18 December 2008.

Citation style for this article: Pebody RG, Begum F, Gates P, Noakes K, Salisbury D. Influenza vaccination coverage in England, 2000-2008. Euro Surveill. 2008;13(51):pij=19074 Available online: http://www.eurosurveillance.org/ViewArticle.aspx?ArticleId $=19074$

T A B L E

Influenza vaccine uptake for 65 years and over by survey year, England, 2000-2008

\begin{tabular}{|l|c|c|c|}
\hline Survey year & $\begin{array}{c}\text { Number of participating } \\
\text { GPs/total GPS }\end{array}$ & $\begin{array}{c}\text { Total number of persons aged } \\
65 \text { years and over vaccinated }\end{array}$ & $\begin{array}{c}\text { Total number of persons aged } \\
65\end{array}$ \\
\hline $2000-1$ & N/A & $4,820,239$ & $\begin{array}{c}\text { Vaccine uptake (\%) } \\
\text { population }\end{array}$ \\
\hline $2001-2$ & N/A & $5,232,826$ & $7,373,157$ \\
\hline $2002-3$ & N/A & $5,487,645$ & $7,726,992$ \\
\hline $2003-4$ & $8,484 / 8,611(99 \%)$ & $5,788,875$ & $8,008,299$ \\
\hline $2004-5$ & $8,147 / 8,675(94 \%)$ & $5,621,381$ & $8,157,671$ \\
\hline $2005-6$ & $8,318 / 8,527(98 \%)$ & $6,122,744$ & $7,870,212$ \\
\hline $2006-7$ & $7,860 / 8,464(93 \%)$ & $59 \%$ & $8,131,513$ \\
\hline $2007-8$ & $7,988 / 8,375(95 \%)$ & $71 \%$ & $7,779,145$ \\
\hline
\end{tabular}

Note: Uptake figures include only those GP practices who have returned confirmation to the survey and reflect data for individuals vaccinated at these premises Data Source: Influenza Immunisation Uptake Monitoring Programme HPA/DH 